\title{
Economical High Frequency Voltage Source Inverter System
}

Ibrahim Fatoul, El-Sayed

Faculty of Engineering and Technology, Helwan Univsity, Cairo, Egypt

" نظلم علكس جهدى السصر بستطبع تحتيل الأكاء الجيد للترددات للعاليه "

أخلاصسـه :

لوجد تطبيتات عطده تحتاج ترى كهربائبه بـردلات عاليه من للمعب تحقيتها بالنظم

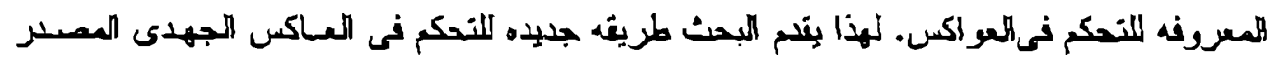

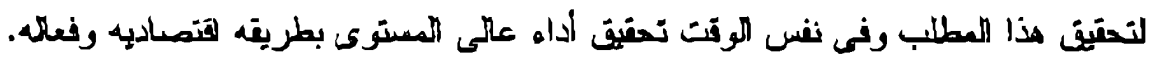

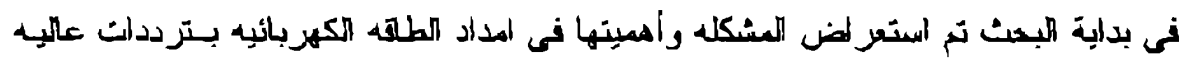

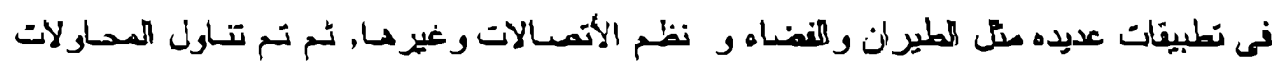

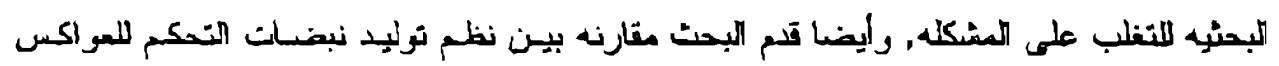

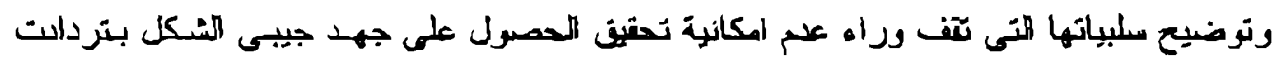

عليه.

بناأ على الفهم العميق والخبره الستغاده من المدراسة التخصيليه لاداه دائرة التوى للعاكس تم

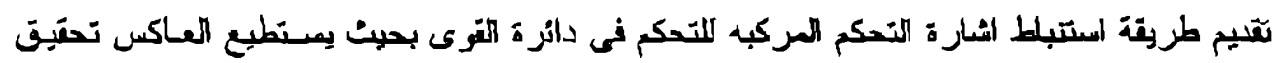

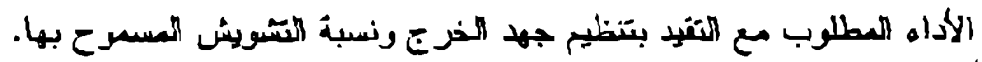

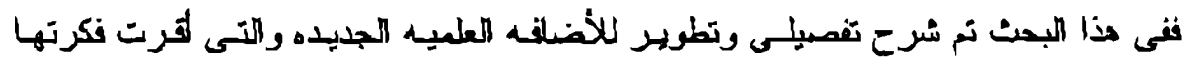

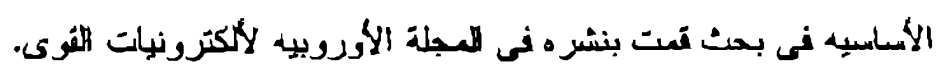

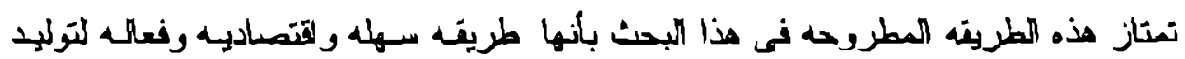

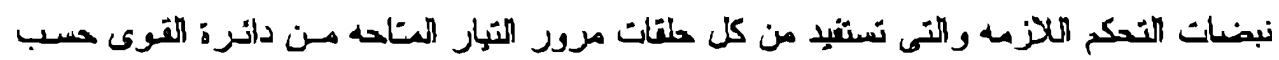

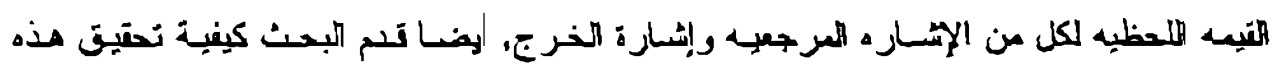

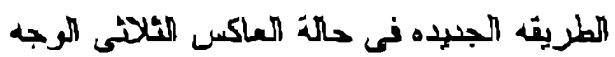

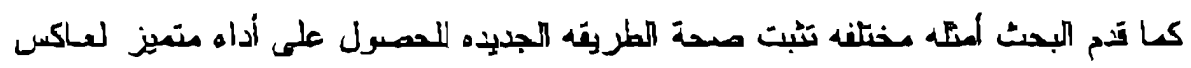

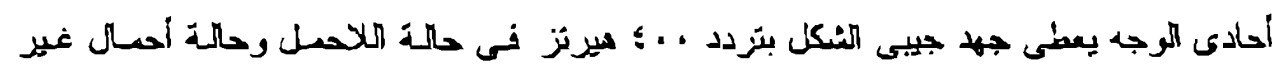

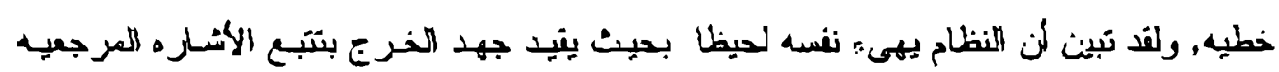
مهما حلث من تغير ات مفاجئه. 
Abstract- High-performance high-frequency inverter systems for voltage source applications such as UPS represent a demanding apptication that cannot be easily realized using conventional PWM inverter modes. New controller structures are necessary to cope with stringent voltage regulation and distortion constraints in the presence of nonlinear loads. This paper presents a simple but intelligent hysteresis controller. It utilizes all possible inverter topologies in addition to feed-forward strategy to achieve low output ripple, minimum switching frequency and excellent transient performance. These features were not available until now. The results verifying the concepts, using pspice program for praccical electronic control circuit and power devices, are presented. Although this paper explains the implementation of the 3-phase control and power circuits that can adapt itself in case of nonlinear and unbalanced luads.

\section{INTRODUCTION}

Many applications such as space/satellite stations, computer stand by power supplies and aircraft on-board power distribution systems require high-quality ac power to be delivered at high frequency. Such systems require harmonically pure sinusoidal output wave forms with very low distortion specifications. These systems have to satisfy tight voltage regulation constraints while supplying nonlinear loads [1],[2]. In order to meet harmonic specifications even in the presence of nonlinear electronic loads the inverter systems have to possess excellent dynamic response characteristics. In addition, 3-phase inverter systems are required to meet strict regulation and distortion constraints under sever load unbalance. The realization of such high-frequency inverter is a very demanding application, especially for systerns requiring high-power densities.

The conventional approach to realize high frequency of inverter systems is through the use of a variable voltage inverter, where a front-end chopper is used to control the voltage. Such systems have slow dynamic performance. The use of the conventional sinusoidal pulse width modulation voltage source inverters can not adapt itself in the presence of nonlinear loads.

Regarding the inverter power circuit, for high frequency operations, the inverter design becomes very critical and its efficiency falls due to the very high switching losses.

Resonance power corversion technology offers many advantages in comparison with PWM one. Among them are low switching losses and low reverse recovery losses due to soft switching. However, most frequency-controlled resonant converters suffer from a wide range of frequencies that is required to regulate output voltage against load and line variations. As a remedy for these problems, several phase-controlled constant operating frequency resonant inverters have been proposed and analyzed [3],[4]. The advantages gained by using resonant imverter schemes are actieved at the expense of higher number of resonant components and high operating frequency.

Using suitable hysteresis modulator, self stabilized controlled inverter scheme can be obtained. The conventional hysteresis modulator switches the bridge to apply cither a positive voltage pulses if the output voltage is less than the reference voltage and vice versa. This control strategy produces high ripples and requires high frequency.

In this paper, the developed hysteresis controller with the hard switching imerter demands lower frequency than the conventional control methods to have equivalent performance based on output ripples. 
The presented control strategy is based on optimal choice of the inverter topology that suit the instantaneous reference and output waves. This in tum reduces the inverter reactive sivitching and subsequent reactive operations.

The paper describes the evolution of adaptive hysteresis modulator for single phase inverter. The feed forward effects and output ripple are discussed. The performance evaluations are given under different load conditions by using pspice practical schematic circuits. For 3-phase operation, it is necessary to use isverter structures that dissolve the coupling between the phases. The different topology and control strategy are explained.

\section{CONVENTIONAL HYSTERESIS MODULATION METHODS}

The principle diagram is shown in Fig. 1. The input of the system is the reference wave that has to be copied in the load by the inverter. The hysteresis tolerance band $(\mathrm{H})$ governs the inverter switching pattern in such a manner as to maintain the mean value of the load voltage at the required value. The instantaneous value of the output voltage obtsined from the fast response sensor is compared with the reference command. Whenever the sensed output signal deviates from the reference by more than a prescribed value, the inverter is operated to reduce the deviation. Thus the output wave is restricted to flow within a channel of width $\mathbf{H}$ that follows the reference wave as shown in Fig. 1(b).

(a)

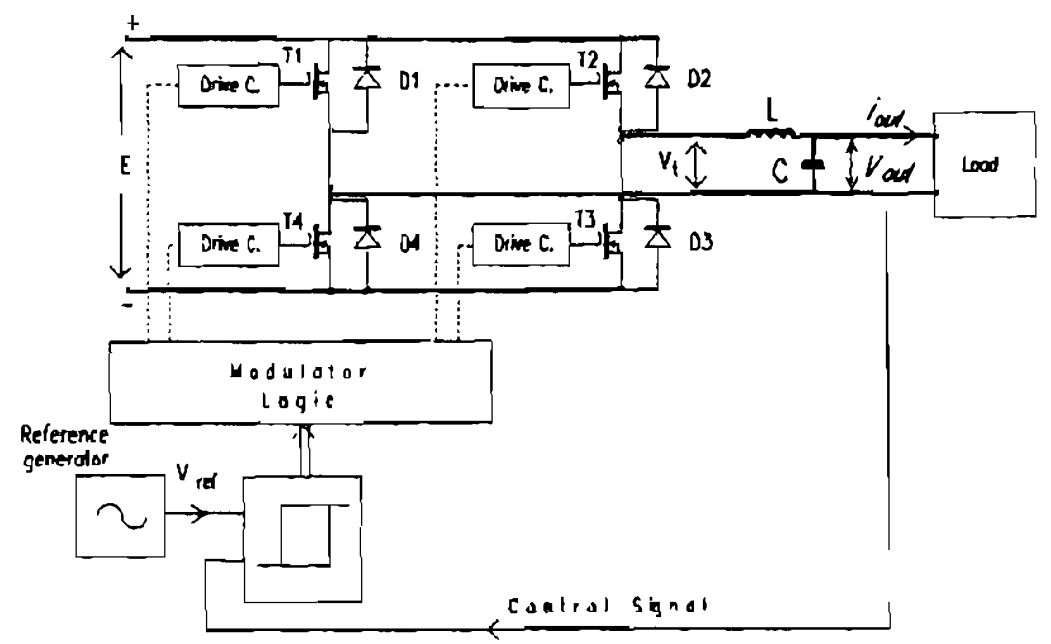

(b)

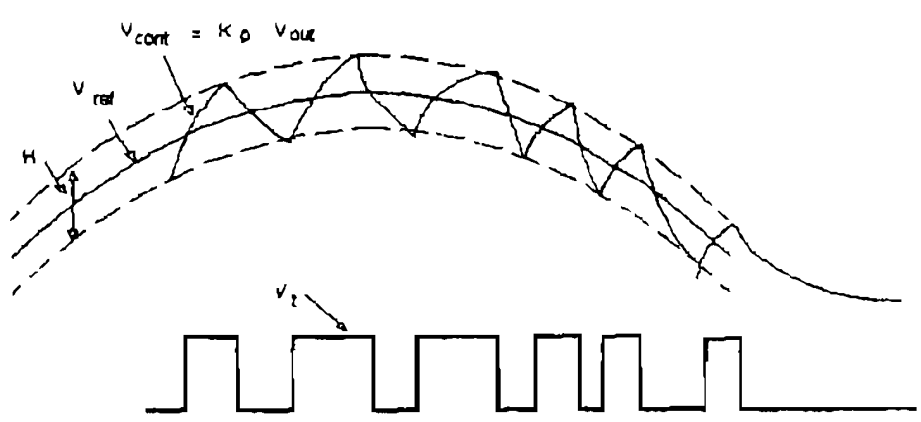

Fig. 1. (a) Hysteresis controlled inverter scheme. (b) Operation principle. 
The deviation of output wave from the reference wave can be controlled by controlling the hysteresis width $\mathrm{H}$ of the controller. The reduction of the width $\mathrm{H}$ causes higher number of inverter switchings. For a given value of $\mathrm{H}$, the frequencies of the harmonics remain at the same level irrespective of the fundamental frequency. Here the pulse patterns that suit the load and supply condition are generated automatically to control the final output through the instantaneous voltage feedback loop. This type of control offers the great advantage of being simple to set up because of its self adapting character, where it does not require PI-regulator which normally has infinite gain for DC only [6].

The system shown in Fig 1(a) employs a controlled output voltage. The combination of the LC filter with the load is considered as the plant of a closed loop feedback system with a sinusoidal reference. Considering the system output state variables $V$ out and its derivative in case of resistive load, the state space equation that describes the system is:

$\left[\begin{array}{l}\dot{V}_{\text {out }} \\ \ddot{V}_{\text {out }}\end{array}\right]=\left[\begin{array}{cc}0 & 1 \\ -1 / \mathrm{LC} & -1 / \mathrm{RC}\end{array}\right]\left[\begin{array}{l}V_{\text {out }} \\ \dot{V}_{\text {out }}\end{array}\right]+\left[\begin{array}{c}0 \\ 1 / \mathrm{LC}\end{array}\right] V t$

The constants of equation (1) depend on the load and filter parameters. The load is statistically variable, especially in nonlinear phase controlled loads, where DC components are required. This is a variable structure plant.

Considering the inverter, the following pairs of devices may be conducting: $\mathrm{T} 1$ and $\mathrm{T} 3, \mathrm{~T} 2$ and $T 4, D 1$ and D3, D2 and D4, T1 and D2, T2 and D1, T3 and D4, T4 and D3. Thus there are three possible levels for the terminal voltage $+E, 0,-E$. The driving sequence for the power devices depends on modulator strategy. Hence, the choice of the type of modulation explicithy defines the controller structure.

\section{A. Bipolar Modulator (BM)}

In this mode the imverter power circuit impresses a closed current pass through the source in either positive or negative direction.

The hysteresis controller shown in Fig. 1(a) develops the necessary driving signals to activate either of the two diagonal pairs $\mathrm{T} 1-\mathrm{T} 3$ and $\mathrm{T} 2-\mathrm{T} 4$ to apply a positive or negative voltage across the inverter terminals.

The system input is the voltage which has to be copied in the load by the inverter. The output voltage is sensed using a voltage divider with ratio $K_{p}$. The output voltage then rises or decay at a rate determined by source, load and filter parameters. The average output voltage is controlled through the instantaneous voltage feedback loop.

Let us define the states that excite the comparator beside the reference input to be the control signal. Normally, the control signal is composed only of the sensed output voltage signal Kp. Vout

The control signal, the reference wave, and the hysteresis value $\mathrm{H}$ determine the switching instants for the inverter in order to form a sinusoidal output wave. This structure enforces the output voltage to be in the tube bounded by the two waves:

$$
\frac{V_{m}}{K_{p}} \sin (w t)+\frac{H}{2} \text {, and } \frac{V_{m}}{K_{p}} \sin (w t)-\frac{H}{2}
$$

Where $V_{m}$ is the peak value of the reference wave. 


\section{B. Unipolar Modulator}

In this mode the inverter power circuit can be driven to impress a current pass either through the source or through a free-wheeling way. To impress a positive voltage, transistors $\mathrm{TI}$ and $\mathrm{T} 3$ should be driven. But to build a free-wheeling way far from the source, T2 should be driven instead of $\mathrm{T3}$. In this case the current is free to pass in any direction through $\mathrm{T1}$, load and D2 or through T2, load and D1 according to inductance trapped energy, capacitor state and the load.

The negative half cycle can be formed by driving $T 4$ along this time and driving $T 2$ or $T 3$. As explained for the positive half cycle, driving $\mathrm{T} 2$ produces negative voltage at the inverter terminals and by driving 13 , the source becomes inactive and the output circuit finds a freewheeling path for the current in any direction.

The structure shown in Fig. 2 develops the necessary driving sigmals for 3-level (unipolar) mode operation. The principle is the same as for bipolar modulator (BM) with additional polarity comparator P-COM The added comparator monitors the pulse patterns generated by the hysteresis comparator where it produces signal that indicates the positive and negative periods of the reference wave. For pusitive period, P-COM activates transistor T1. During this time the output terminal will be switched between $-E$ and 0 according to the generated pattem by the hysteresis controller HCOM. In a similar manner, $\mathrm{T} 4$ will be activated for negative period to produce terminal voltage of $-E$ or 0 . In this control strategy, the signal produced by the HCOM determines the terminal voltage magnitude to be $E$ or $O V$, while the polarity comparator P-COM determines the polarity of the terminal voltage.

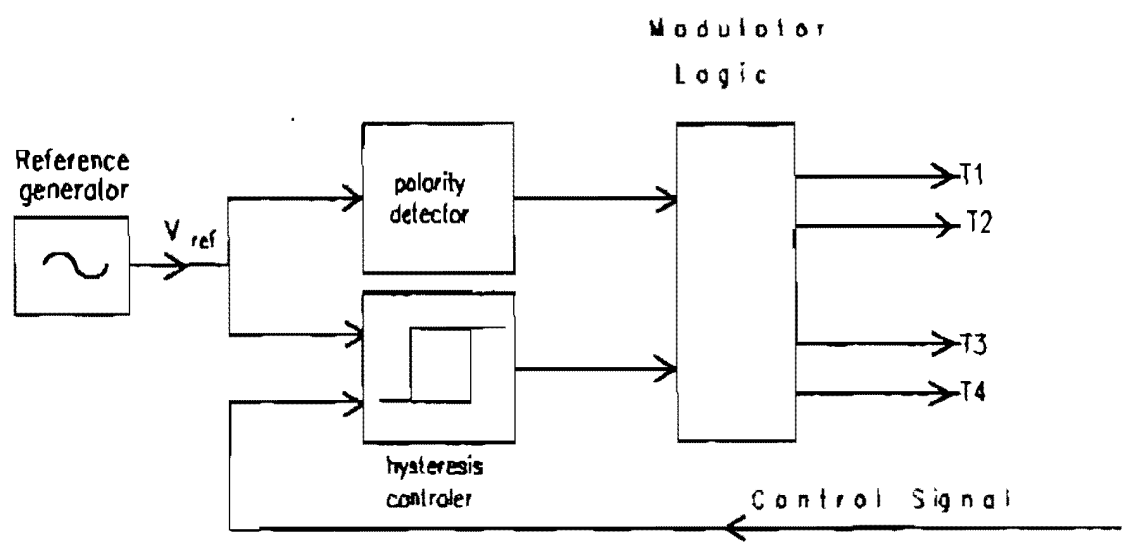

Fig. 2: Block diagram for unipolar modulator.

It is known that the bipolar mode requires high switching frequency that increases transistor losses. On other side, in case of unipolar mode, the output may not follow the reference wave at falling side [8]. This depends mainly on the load time constant and the decay rate of the reference wave. This is not happen in case of bipolar because it can forces the excess energy to return back into the supply.

In view of energy transfer, The bipolar mode causes high reactive power between DC source and filter circuit. This explains why the switching density is high. In other words, it can be said that this mode demands more reactive switchings and reactive inverter operation time. In case of unipolar mode, also, there are reactive power that does not return to the DC supply but oscillate between filter elements through inverter devices. Thus, unipolar mode exhibits also reactive switching and reactive operation but less than in bipolar mode case. 


\section{FREFPOLAR MODULATOR}

\section{A. Principle of Operation}

In this mode, the driving strategy of the power transistors is different, where the inverter terminal voltage can be positive or negative or zero or floating at any time. In bipolar case, the controller has two freedoms only $+E$ or $-E$. Also in unipolar, the controller restricts the operation freedoms to be $+E$ or 0 in positive period and to $-E$ or 0 in negative period. This means that the unipolar mode also has only two freedoms as bipolar one.

(a)

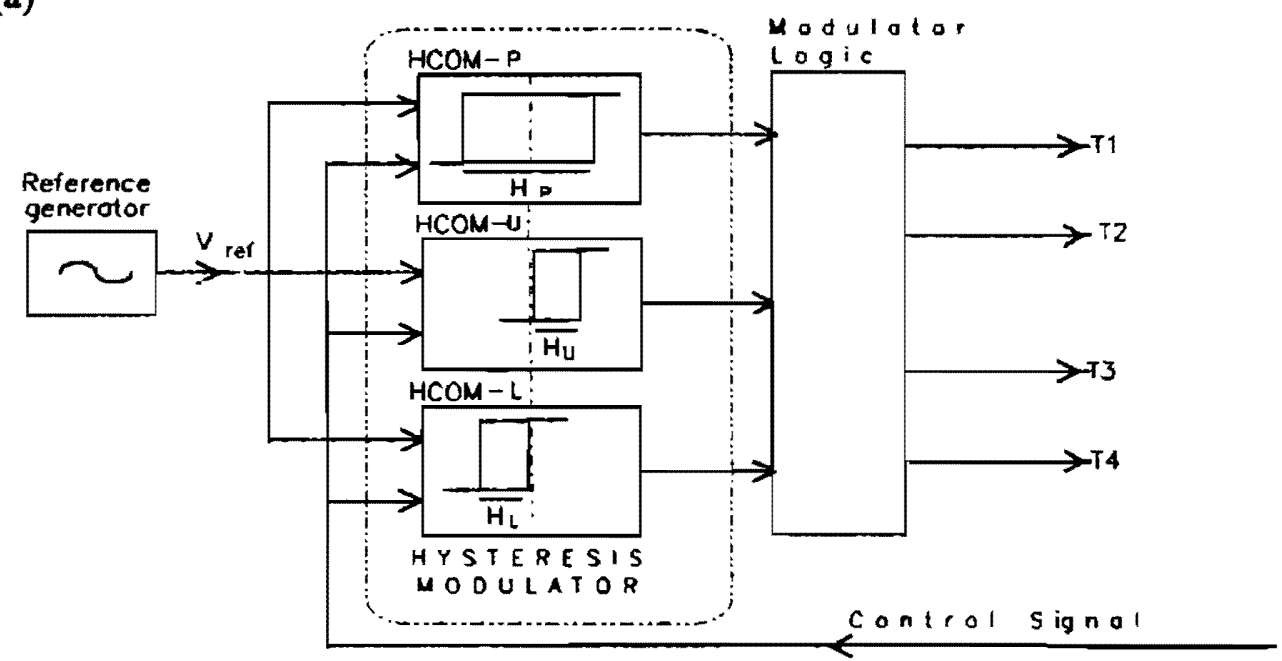

(b)

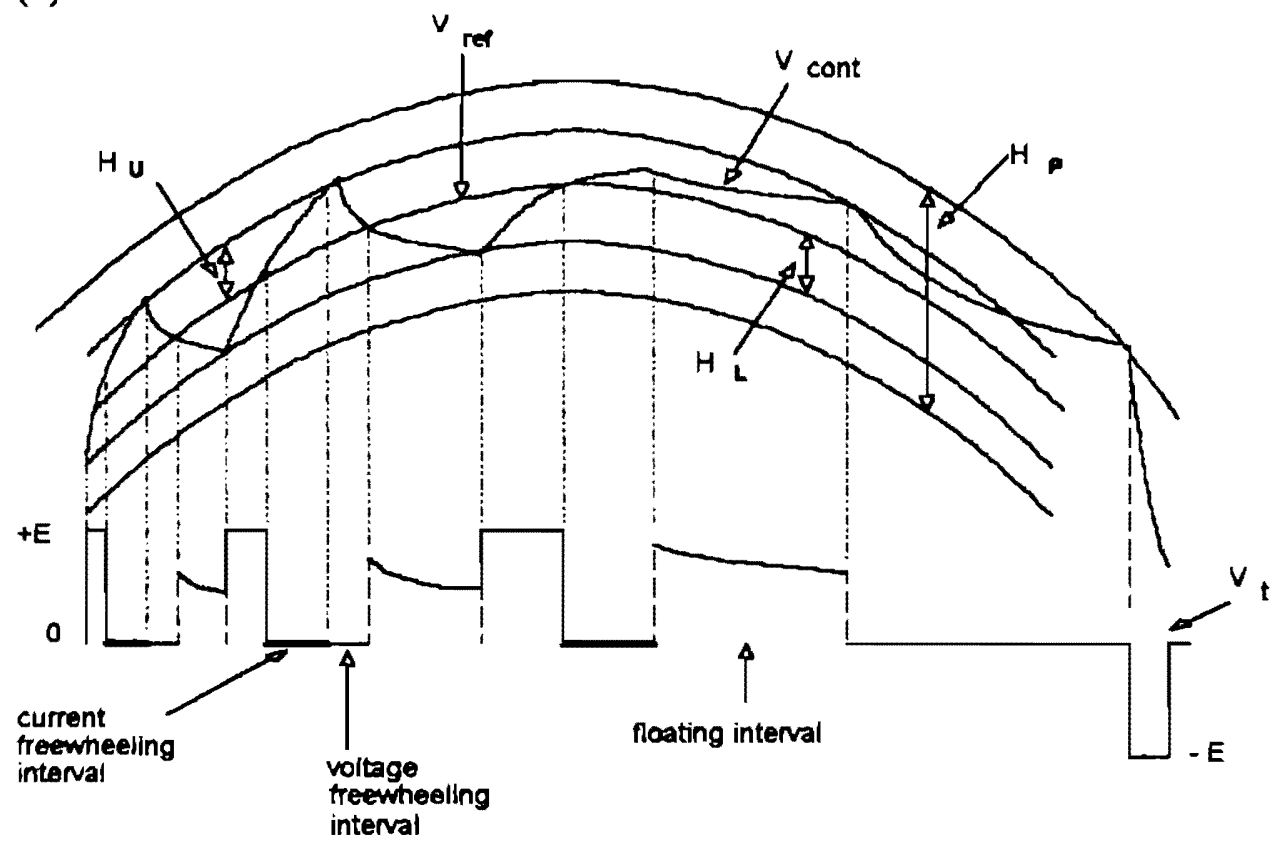

Fig. 3.(a) Proposed control structure for the freepolar hysteresis modulator

(b) operating principle. 
The new hysteresis modulator shown in Fig. 3(a) uses extra degree of freedoms and is free to use the best state irrespective of the reference half cycle. As shown in Fig. 3(b), it lets current freewheeling when the control signal $V$ cont tends to cross-up the upper boundary of the lower band HL. After the current freewheeling the modulator forces the power circuit to be in the floating state as long as the control signal lies within the tolerance band HU. In this case, if the output rises more, the modulator forms a freewheeling way for discharging the capacitor (voltage freewheeling). If the control signal is still higher than the upper band in spite of the forgoing actions, the modulator switches the negative voltage state that forces the output to retum back in the tolerance band. Thus, the freepolar modulator strategy will be defined by the logic block. Where it provides the transistor-control signals according to the states of the three hysteresis compactors: U-HCOM, L-HCOM, P-HCOM shown in Fig. 3(a).

To drive the inverter power circuit for freepolar PWM mode, firstly, the polarity signal comparator in the unipolar controllet is modified to be a hysteresis one (P-HCOM) that compares the reference signal $V_{r}$ with the control signal $V_{\text {cont }}$ as shown in Fig. 3. Clearty, the polarity comparator ( $\mathrm{P}-\mathrm{HCOM}$ ) will be in active state (T1 active and T4 inactive), when the control signal Vcont crosses positively the upper boundary $V_{r}+\mathrm{HP}$. It nolds this case till the control signal crosses negatively the lower boundary $V_{r-H P}$ and vice versa. Hence, the poles + and - are selected according to the deviation between $V_{r}$ and $V_{c o n t}$ instead of the reference signal polarity in case of unipolar mode.

Secondly, the other transistors $\mathrm{T} 2$ and $\mathrm{T} 3$ are driven so that the extra degree of freedoms offered by the basic inverter topology arc utilized. The potentially valuable states can be selected in the best sequence using the following logical statements:

IF P-HCOM is active (T1 active and T4 Inactive)

$$
\begin{aligned}
& \begin{array}{c}
\text { Output } \\
\text { state }
\end{array} \\
& V_{t}=0 \\
& V_{t}= \\
& V_{t}=+\mathrm{E} \\
& V_{t}=
\end{aligned}
$$

"T2 will become active, when the control signal crosses positively the upper band of HU"

"T2 will become inactive, when the control signal crosses negatively the lower band of HU"

"T3 will become active, when the control signal crosses negatively the lower band of $H L "$

"T3 will become inactive, when the control signal crosses positivety the upper band of $\mathrm{HL}^{\prime \prime}$

IF P-HCOM is inacive

(T1 inactive and $\mathrm{T} 4$ active)

"T2 will become active, when the control signal crosses positively the upper band of $H U^{\prime \prime}$

"T2 will become inactive, when the control signal crosses uegatively the lower bond of $\mathrm{HU}^{\prime \prime}$

"T3 will become active, when the control signal crosses negatively the lower band of $H^{\text {" }}$

"T3 will become iractive, when the control signal crosses positively the upper band of $H^{\prime \prime}$

$$
\begin{aligned}
& V_{t}=-\mathrm{E} \\
& V_{t}=- \\
& V_{t}=0 \\
& V_{t}=\sim
\end{aligned}
$$


Here, the polarity signal flips when the present state is not enough to control the output wave to be in the prescribed band. This polarity sigral gives us freedom to generate $+E$ or $-E$ whenever it is necessary. Unlike unipolar and bipolar, in positive period the inverter terminal voltage can be switched between the state $+\mathrm{E}$ and the state $\sim$ (floating) or between $\sim$ and 0 (frecwheeling) or between 0 and -E sequentially for any time width. For example (in case of positive period) if the switching from $+\mathrm{E}$ to $\sim$ (floating state), and switching from $\sim$ to 0 (voltage freewheeling) not enough to control the output, the polarity signal will be inverted.

Fig 3(b) demonstrates the operation mechanism of the hysteresis modulator during positive period. When the control signal crosses positivety the upper boundary of the desired band HIL (L-HCOM become inactive), the modulator leaves only T1 ON. Hence the inductance trapped energy finds a freewheeling path through $\mathrm{T} 1$ and D2 (current freewheeling). This prolongs capacitor charging. After the current freewheeling the output circuit becomes in floating state from the irverter side. During this interval, the capacitor voltage decay according to the load only. If the control signal, in spite of this action, still rises (or the reference wave decay rapidly) out side the desired tolerance band HU, the second upper comparator (U-HCOM) will activates T2. This action causes the capacitor to discharge through the freewheeling path D1 and T2. Therefore, the output voltage decays faster than in floating state. If the output is still going to fly away from the desired band, the outer comparator (polarity comparator P-HCOM) will flip when the control signal crosses positively the upper boundary of HP. This flip will activate T4 instead of $\mathrm{T} 1$ to impress a negative voltage that forces the output to return into the desired band.

\section{B. Regulation and Ripple Control}

The regulation quatity of the output voltage is the most important specification of UPS system. Excellent transient performance of the self stabilized hysteresis controller is essential for tight regulation in the presence of switched loads.

It can easily be seen that the UPS system is a variable structure plant[equ.(1)]. Clearty, the control input to

output voltage transfer function [Fig. 4] depends mainly on the load. The load-dependent phase lag between input and output (caused by inductance trapped energy) may produce uncontrolled ripple especially during switched nonlinear loads. The dynamic performance and the ripple control can be improved by modifying the control signal $V$ cont.

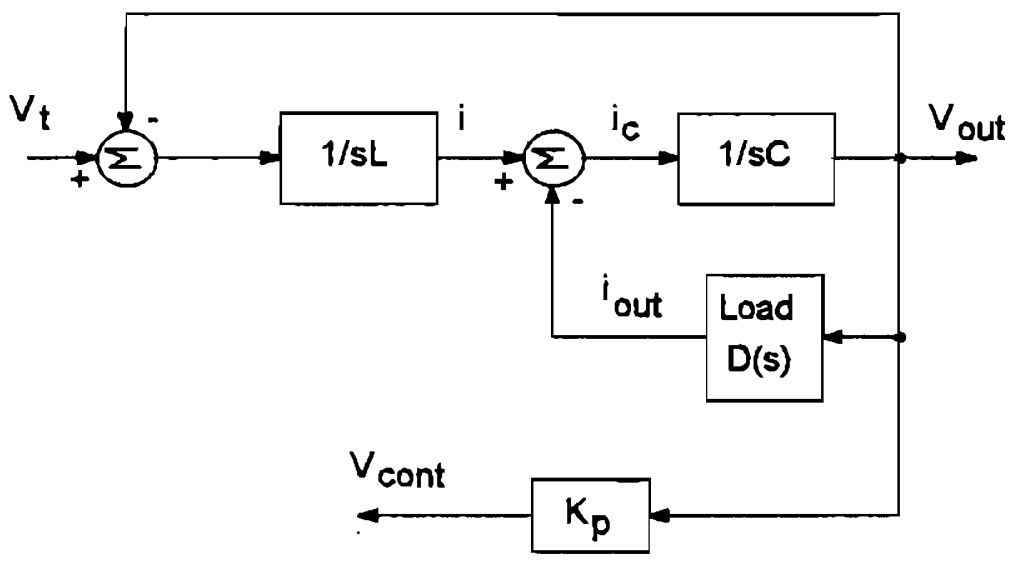

Fig 4 Block diagram of the plant. 


\section{Control signal}

The insight understanding for the operation of the system helps us to find an effective way to make the output ripple under control irrespective of filter and load parameters.

The equation that describes the output response can be written as:

$\frac{d V_{\text {ow }}}{d t}=\frac{i-i \text { ias }}{C}$

The investigation of equation (2) shows that the rate of change of the output voltage gives a measure of the inductance trapped energy at no load and a measure of the excess energy at loading case. This trapped energy prolongs the charging time that charges the capacitor over. For example, if the inductance current is equal to the load current, the over charging will not occur. Clearly, the state $d V$ out $d t$ is an important signal that can be used to modify the control signal that judges the hysteresis controller. Hence, the control signal $V_{\text {con }}$ should be composed of the derivative in addition to the proportional of the ourput voltage signal as follow.

$V_{\text {cont }}=\mathrm{K}$. $. V_{\text {out }}+\mathrm{Kd} . d V_{\text {out }} / d t$

Where $\mathrm{Kd}$ is a constant that determines the weight of the derivative in the control signal.

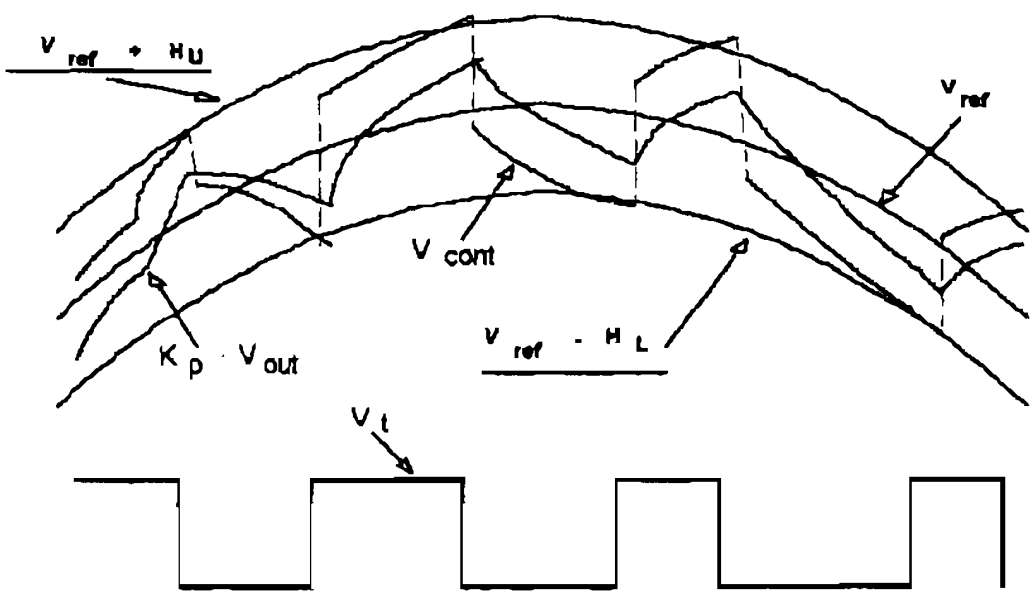

Fig 5. Principle operation of the modified control signal

This signal with the reference one determines the suitable switching instant so that the output remains in the prescribed tolerance. Here the inverter transistors are driven in such a way that the sum of the sensed states $\mathrm{K}_{\mathrm{p}} . V_{\text {out }}$ and $\mathrm{Kd} . d V_{\text {out }} / d t$ is confined between the two waves that are spaced by $-\mathrm{HU}$ and $-\mathrm{HL}$ from the reference one. This means that the output state Vout will be controlled so that:

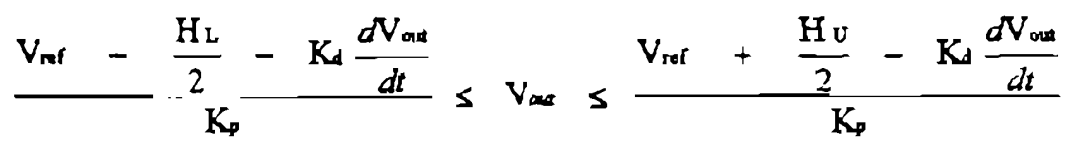

Fig. 5 demonstrates the modified control signal effects on the switching instants. The switching will occurs when the output crosses the value: 


$$
V_{\text {or }}=\frac{V_{\text {ref }}+\frac{H}{2}-K_{d} \frac{i-i_{\text {aut }}}{C}}{K_{p}}
$$

$$
V_{\text {out }}=\frac{\mathrm{V}_{\text {rof }}-\frac{\mathrm{H}}{2}-\mathrm{K}_{\mathrm{t}} \frac{i-i_{0 u t}}{\mathrm{C}}}{\mathrm{K}_{\mathrm{p}}}
$$

These switching constraints are not only function of the output value but also of its speed of change. This means that: if the output changes slowly, the switching occurs nearty when the signal $\mathrm{Kp}$. Vout crosses the tolerance band. But in case of rapidty change, the switching occurs eartier than before. This leads to make the excess energy part not a burden but a useful part in the control process.

In view of the regulation quality, the modified control signal has load current component jout that can affect the modulator performance directly without delay as shown in Fig. 6. This improves the system dynamic performance. Also, the inductance current component $i$ is a measure of how much the rapped energy is. This energy depends on the time integral of the difference between the DC voltage $\mathrm{E}$ and the output Vout. Hence, the component $i$ helps the modulator to keep the output ripple under control especially in the sever cases of light load and low output values.

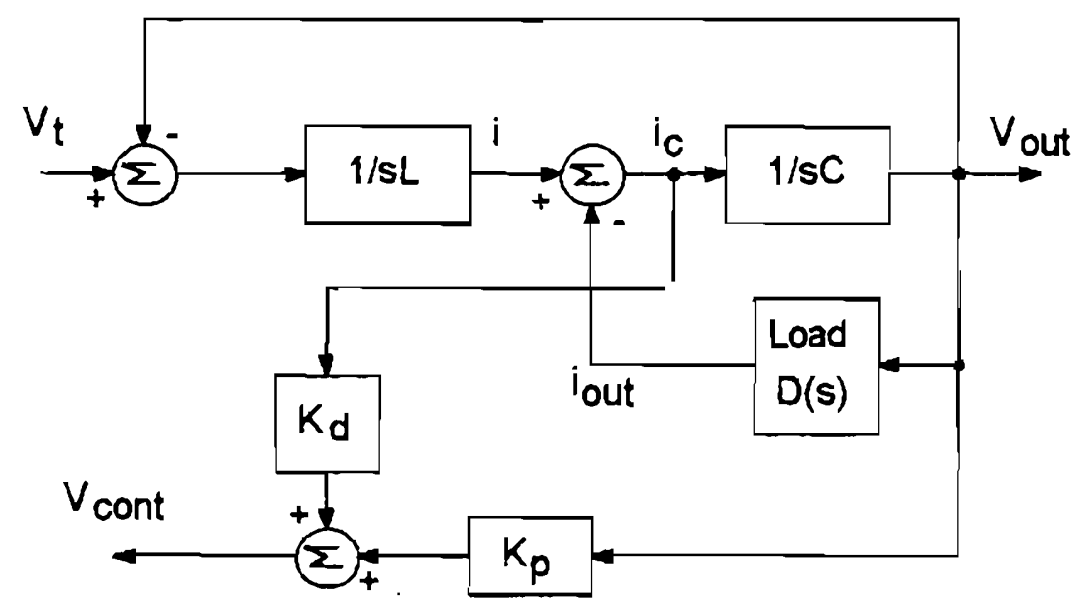

Fig. 6 Block diagram of the plant with the modified control signal

\section{Evaluation}

The proposed control scheme shows more flexibility and uses extra degree of freedom. Clearty, the performances in Fig. 7 show that the proposed scheme is fast enough to generate a sinusoidal $400 \mathrm{~Hz}$ voltage wave under different conditions. The controller can control the power circuit to impress any state of $+E, \sim, 0$, and $-E$ in any half cycle [Fig. 7(a)]. These can be used to control the output voltage whenever is necessary. 
The presented modulator adapts itself by generating the suitable PWM pattem to judge the output to be within the tolerance band. In case of fast decay the controller reverses the inverter terminal voltage $V_{t}$ even in the positive period as shown in Fig. 7(a)-(d). This forces the output to follow the reference wave. But in case of unipolar, the controller can not reverse the inverter terminal voltage in the positive period. Hence the output remains out of control in case of unipolar till the reference wave changes its sign.

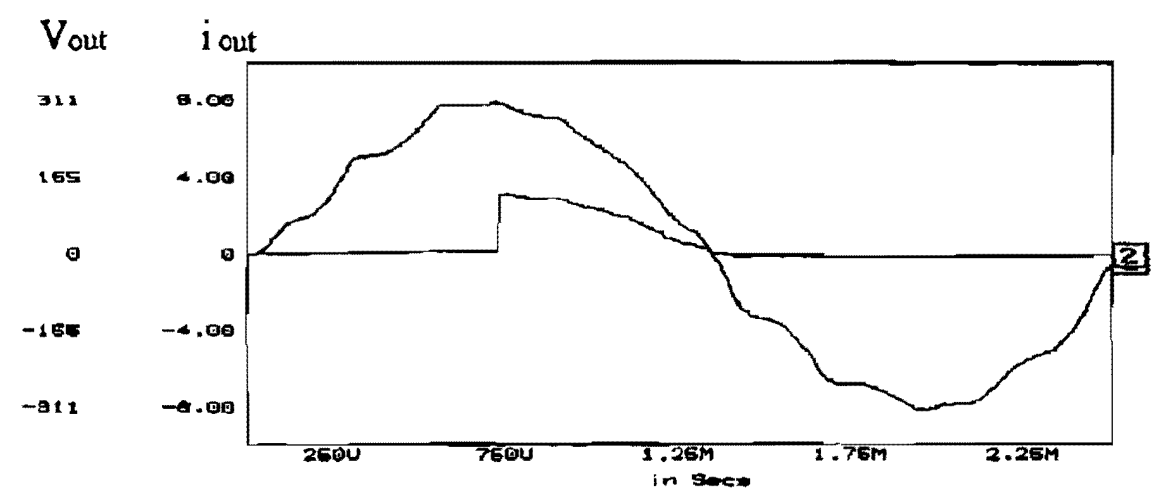

$\mathrm{V}_{\mathrm{t}}$

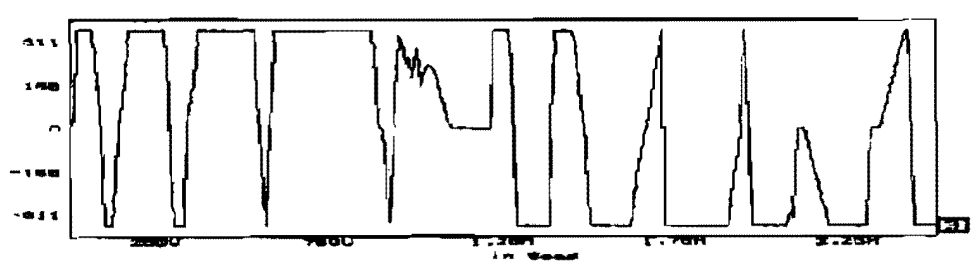

Fig. 7(a) switched load , $\mathrm{L}=5 \mathrm{mH}, \quad \mathrm{C}=5 \mathrm{uF}, \mathrm{HU}=\mathrm{HL}=2 \% \mathrm{HP}=6 \%$

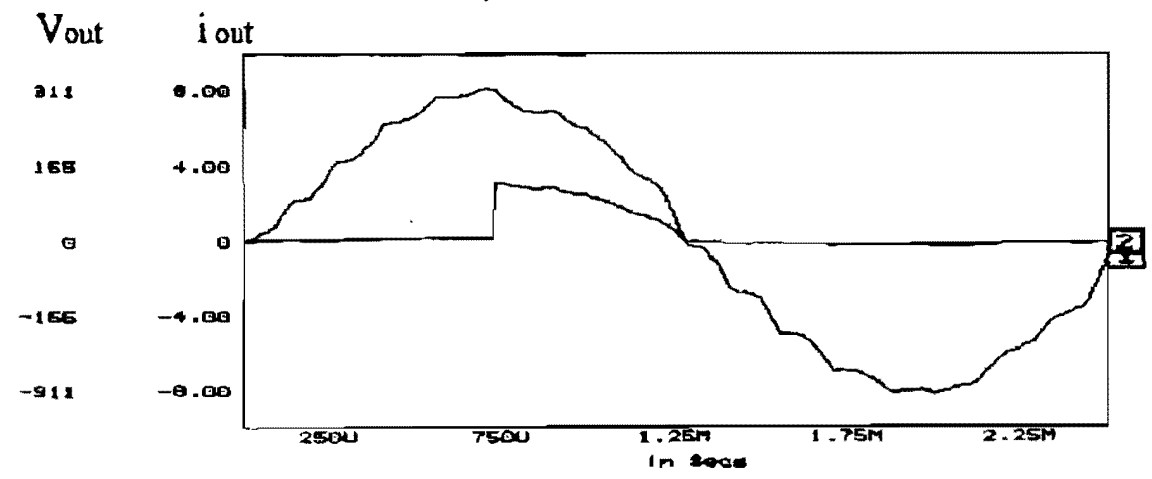

$\mathrm{V}_{\mathrm{t}}$

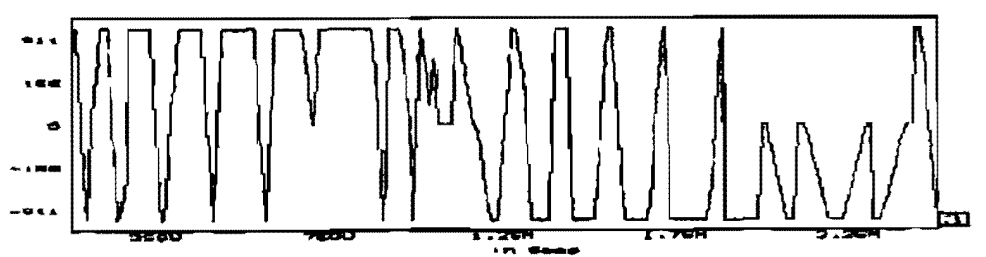

Fig. 7 (b) switched load , L =2.5mH, C=5uF, $\mathrm{HU}=\mathrm{HL}=1 \% \mathrm{HP}=6 \%$ 


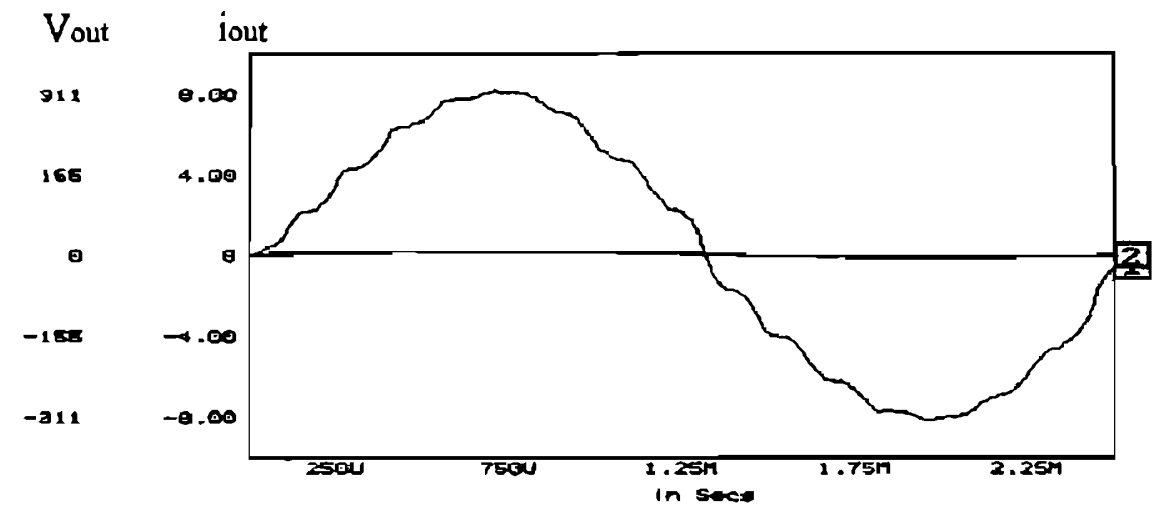

$\mathrm{V}_{\mathrm{t}}$

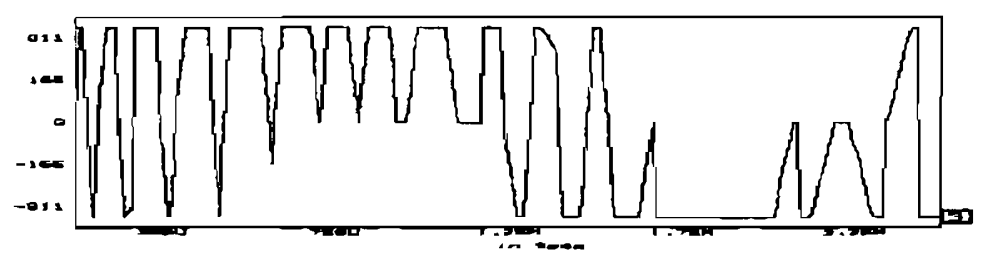

Veont

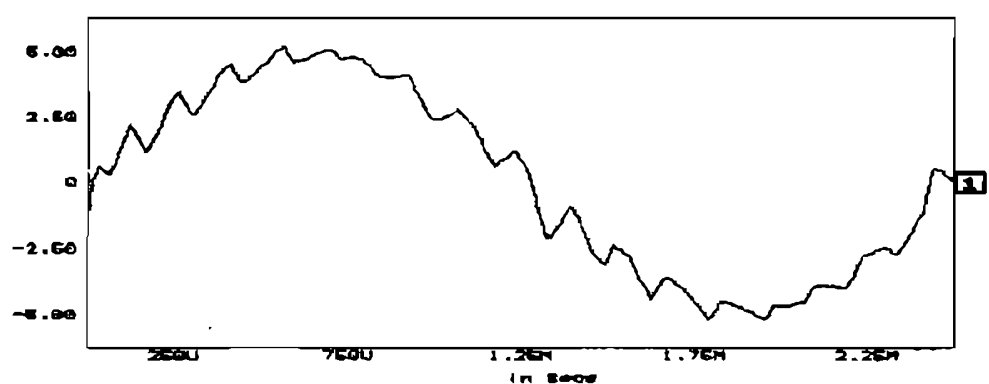

Fig. $7(\mathrm{c})$ no load, $\mathrm{L}=2.5 \mathrm{mH}, \mathrm{C}=5 \mathrm{uF}, \mathrm{HU}=\mathrm{HL}=1 \% \mathrm{HP}=6 \%$

The floating case is obtained when the output remains within the upper tolerance band HU for a considerable time interval as shown in Fig. 7(a). During this time the capacitor discharge rate is nearty similar to the decay rate of the reference wave. Also, the response in Fig 7 (b) shows that the high frequency ripples are controlled also during no load time. This explains the considerable effects of the modified control signal. The system response in Fig. 7(a),(b) show that the switched load causes small fluctuations at the output wave. But the terminal voltage $V_{t}$ response points out that the modulator reaction is nearty instantaneous. Hence, It can be concluded that the fluctuations do not depend on the controller but depend on the inventer strength (input DC voltage) and devices switching delay. The transient performance can be improved by increasing the input DC voltage. This shows that the presented scheme can achieve excellent steady-state and transient performance simultaneousty. For loading case in Fig. 7(d), the ripples in rising and decaying case are controlled as in case of no load

It is clear that the control signal has high ripples that cause switching at suitable time instants according to the load and the inductance currents. For loading case in Fig. $7(d)$, the control signal has lower ripples than in no load case [Fig. 7(c)] with similar excellent output wave shape. 
Regarding parameter variations $(L, C$, and $H$ ), the system adapts itself as shown for $L=5 \mathrm{mH}$ $\mathrm{HU}=\mathrm{Hl}=2 \%$ [Fig. 7(a)] and for $\mathrm{L}=2.5 \mathrm{mH}$ and $\mathrm{HU}=\mathrm{HL}=1 \%$ [Fig. 7(b)]. This explains that the presented modulator can adapt and stabilize its output withour additional PI controller as the other systems normally need.

Conceming the switching frequency, there is no considerable change due to loading effect and it is in the range of $10 \mathrm{kHz}$
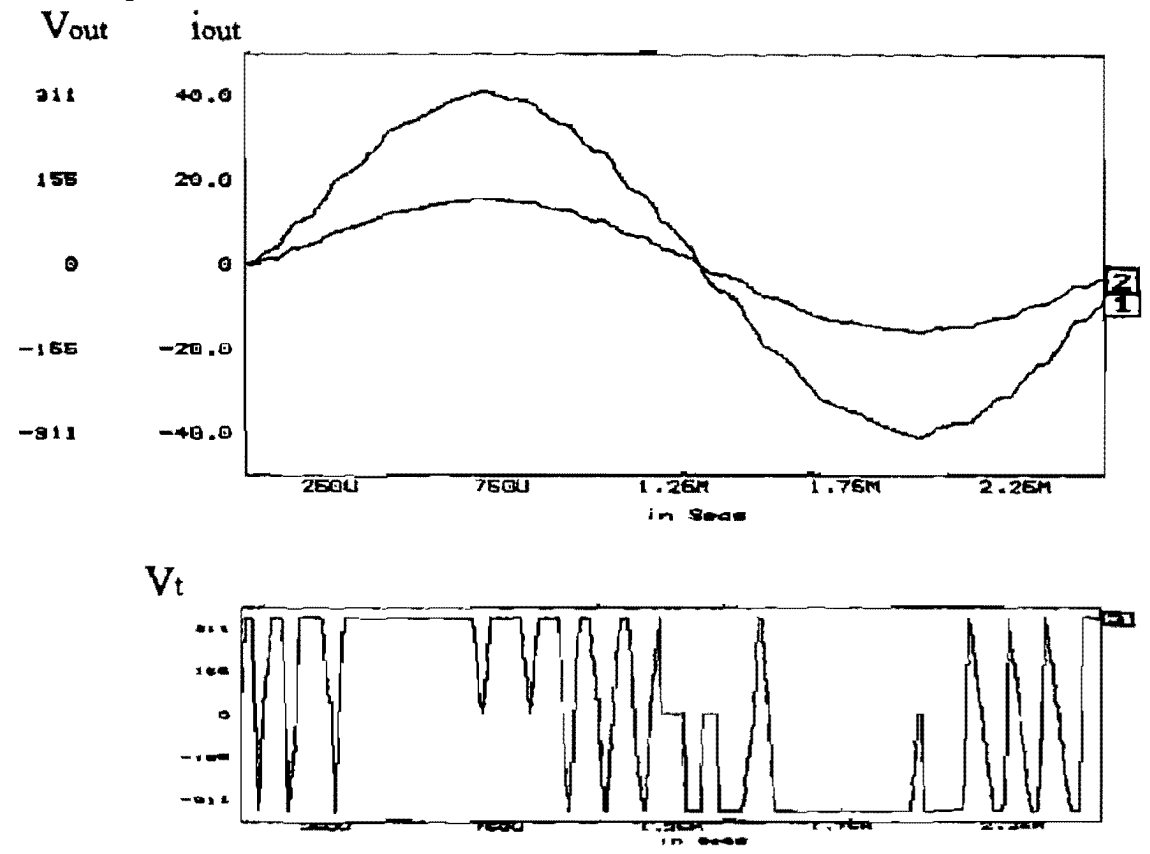

$V_{\text {cont }}$

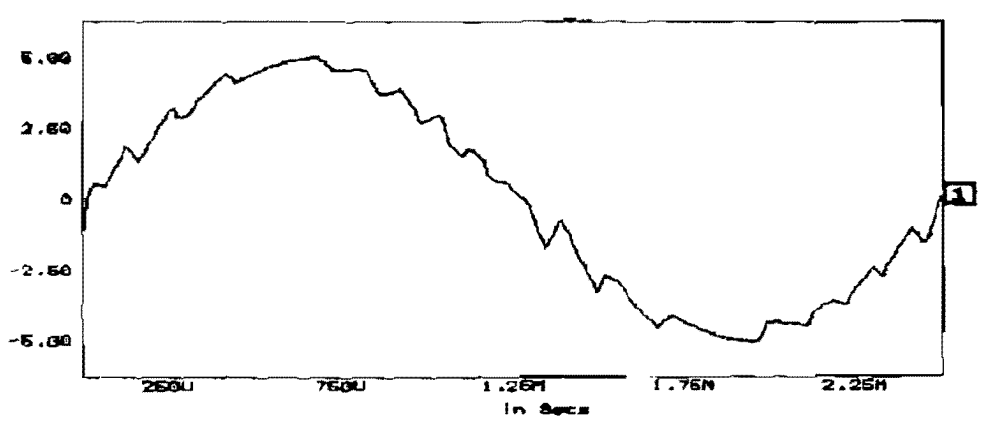

Fig. $7($ d) normal load, $L=2.5 \mathrm{mH}, \mathrm{C}=5 \mathrm{uF}$, $\mathrm{HU}=\mathrm{HL}=1 \% \mathrm{HP}=6 \%$

\section{Three Phase Inverter}

In view of the demanding three phase applications requirements of the inverter system, the inverter should have the capability to supply single-phase loads independently, balanced threephase loads, nonlinear or switched loads, etc. To obtain these requirements, the invener should provide uncoupled topologies for the phases.

There are several configurations for providing more freedoms than the conventional threephase inverter circuit. 
The inverter leg shown in Fig 8(a) is described in details in [10], [11]. In this configuration, at least two switches of the inverter leg are in the off-state. The output terminal can be switched to one of the poles $+E,-E, 0$. Thus the imverter can provide 27 switching states, wtile the ordinary one can onty 8 states. The alternative configuration shown in Fig. 8(b) provides 4-wire output connection including a neutral terminal so that balanced voltage can be produced to unbalanced load. These configurations are preferable for handling unbalanced loads.

The hysteresis modulators, as in single-phase case, drive the four leg switches so that each phase voltage follows its reference wave. Where each phase has, independently from the others, the same degree of freedoms as the single phase imverter scheme. The onty difference is that the modulator logic block should match between the demanded states of the modulators. For example, in Fig. 8(b) phase 1 can get state 0 by switching either Tul and Tu2 or TI1 and T12. Hence, the logic block decides the suitable choice according to the demanded states of the other phases.

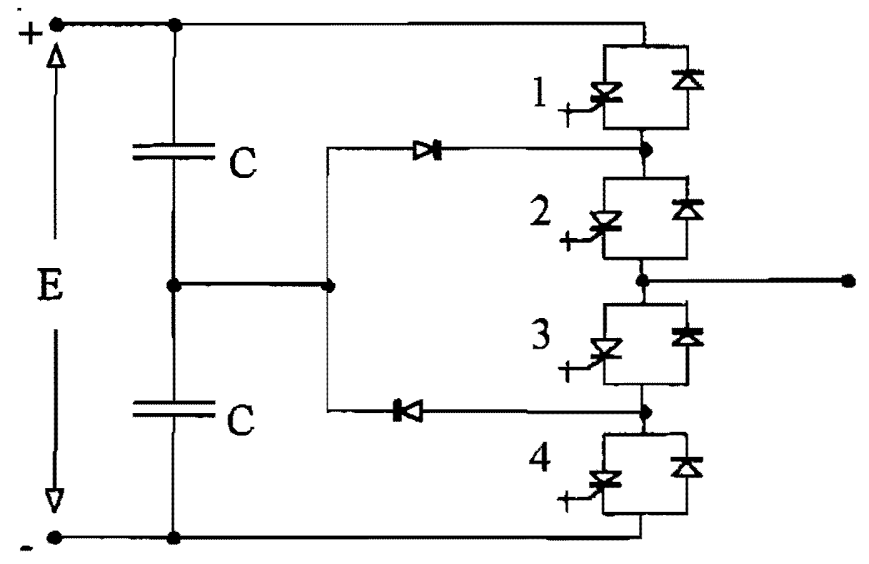

Fig 8(a) Schematic diagram of 3-level imverter leg.

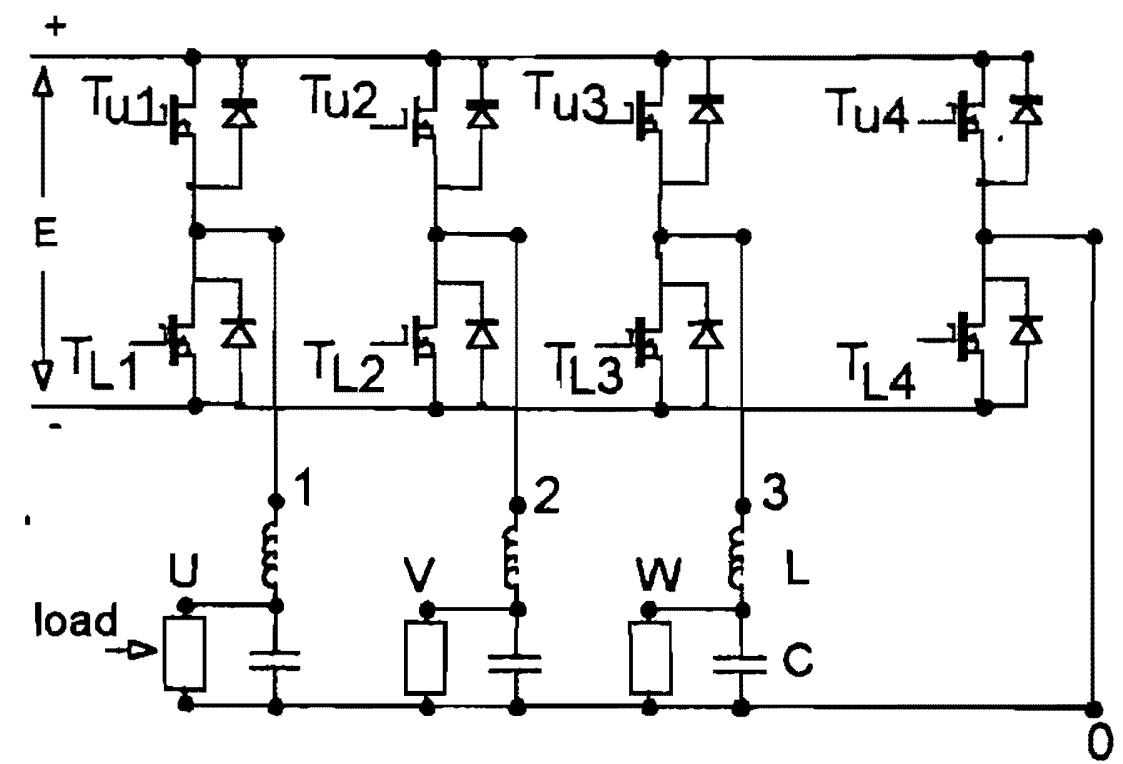

Fig. 8(b) Schematic diagram of 4-leg three-phase inverter.. 


\section{V: Conclusion}

A simple intelligent modulator to realizing a high performance high frequency inverter system has been presented. The control strategy is based on the optimal choice of the inverter topology that suit the instantaneous reference and output waves.

The control signal composed of output voltage, load current and imverter output current has considerable effects on the performance. It reduces the inverter reactive switching and subsequent reactive operations. Hence, the scheme has low output ripple, minimum switching frequency and excellent transient performance. Moreover, it is not sensitive for parameter's variation. Presented records have showed, for different load conditions, the superiority than the conventional methods. The proposed controller structure is very simple, not sensitive to the noise and easy to tune.

\section{References}

[1] G. Venkataramanan,D. M. Divan, and T. M. Jahns, "Discrete Pulse Modulation Strategies for High-Frequency Inverter Systems", IEEE Trans. Power Electron., vol. 8, Pp. 279-287, Juły 1993.

[2] H. Yonemori, Y. Nishidas M. Nakaoka, and F. Harashima "Instantaneous Voltage Control-Based Sinusoidal CVCF Inverter with High-Frequency Resonant AC Iink and its UPS System Application" Conf.Rec. European Conference on Power Electronics and Applications Aachen, 1989, pp. 341-346.

[3] D. Czarkowski, and M. K. Kazimierczuk, "Phase-Controlled Series-Parallel Resonant Converter", IEEE Trans. Power Electron, vol. 8, pp. 309-319, July 1993.

[4] S. Nagai, A. Chibani, M. Nakaoka, and H. Ogiwara, "A New Phase-Shifting PWM Regulated-Mode Resonant Inverter using Static Induction Power Devices for InductionHeating and -Melting Applications" Conf.Rec. European Conference on Power Electronics and Applications Aachen, 1989, pp.347-352.

[5] M. Brunello, J. P. Ferrieux, and J. Perard, "Use of Resonant Devices in Uninterruptible Power Supplies" Conf.Rec. European Conference on Power Electronics and Applications Aachen, 1989, pp. 683-688.

[6] M. P. Kazmierkowski, M. A. Dzicniakowski, and W. Sulkowski, "Novel Curtent Regulators for VSI-PWM Inverters" Conf.Rec. European Conference on-Power Electronics and Applications Aachen, 1989, pp. 23-28.

[7] S. Ostlund "Influence of the control principle on a high-voltage inverter system for reduction of traction-transformer weight" ${ }^{\mathrm{N}}$, Conf.Rec. European Conference on Power Electromics and Applications Aachen, 1989, pp. 561-566.

[8] R.G. Palaniappan, and J. Vithayathil, "A control strategy for reference wave adaptive current generation" IEEE Transaction on Industrial Electronies and Control Instrumentation Vol. IECI-27, No. 2, May 1980, pp. 92-96.

[9] Bowes, S.R.; Mount M.J., "Microprocessor control of PWM inverters", IEEE Proc., Vol. 128 , no. 6, 1981, pp. 293-305.

[10] J. K. Steinke, "Grundlagen fur die Entwicklung eines Steuerverfahrens fur GTODreipunktwechselrichter fur Traktionsantriebe", etz Archiv 7, 1988, H.7, pp.215-220.

[11] B. Velaerts, P. Mathys, "Microcontroller-Based, Multi-Mode 3-Level Pulse-Width Modulator", EPE Joumal, October 2/1991, pp. 133-138. 